\title{
How have women's participation and fields of study choice in higher education evolved over time?
}

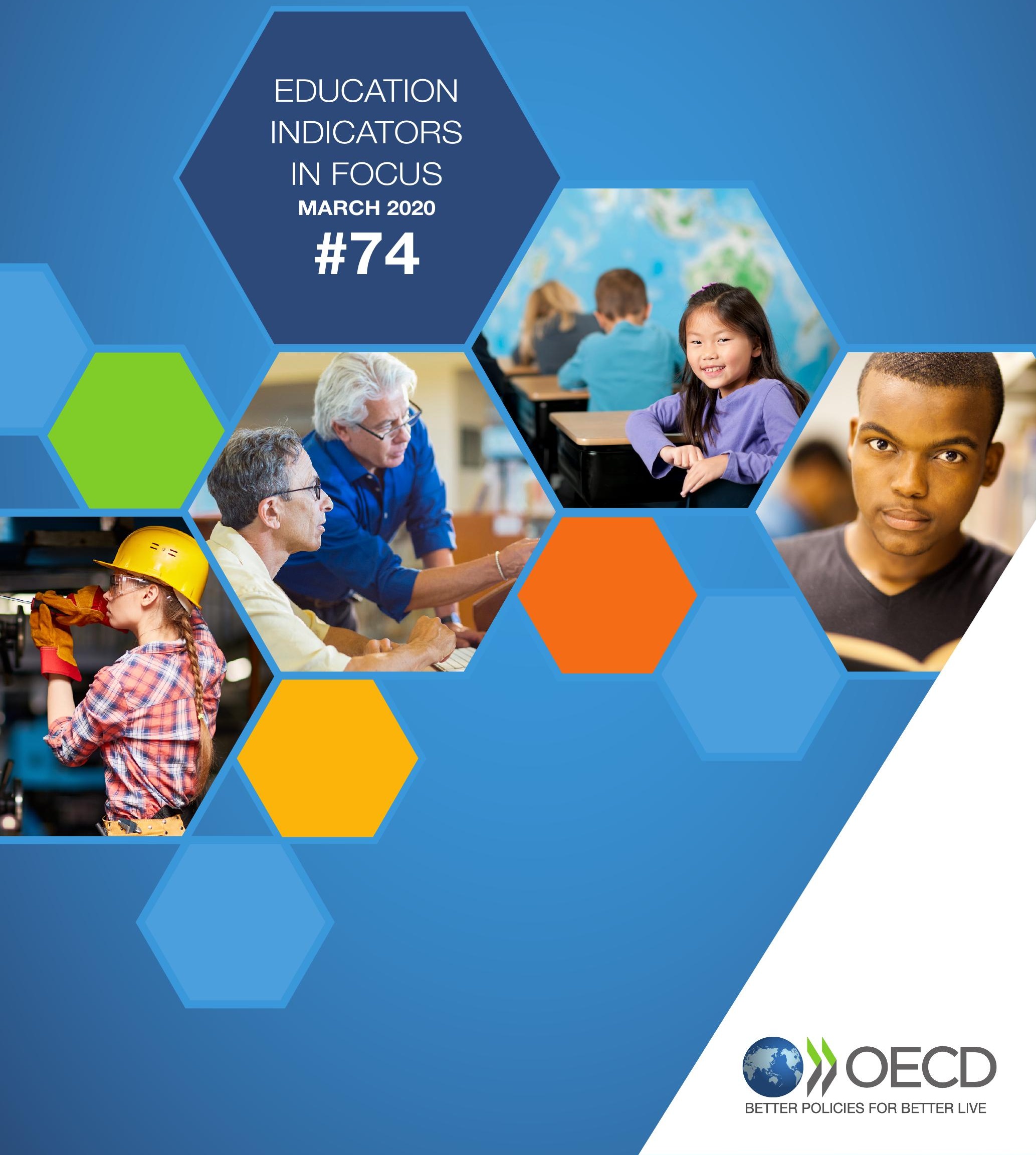


- The last few decades have been marked by faster growth among women in participation in higher education than among men, which has reversed gender inequalities in tertiary attainment in almost all OECD and partner countries. On average across OECD countries, $51 \%$ of $25-34$ year-old women held a tertiary degree in 2017 , compared to $38 \%$ of 25-34 year-old men.

- However, strong barriers are still preventing women from choosing science-related fields and careers, despite having the ability to do so. They predominantly choose the fields of education, and health and welfare, while men still predominate in science, technology, engineering and mathematics (STEM).

- Women's earnings in the workplace still lag behind men's and their progression is constrained by many societal and economic factors. Even when they hold the same degree, women still earn less on average than their male peers for all fields of study and in all OECD and partner countries.

\section{More and more women are earning a tertiary qualification in OECD countries...}

Over the last decade, women's participation in higher education has significantly expanded in OECD and partner countries. In almost all OECD countries, the proportion of tertiary-educated women is higher than the proportion of tertiary-educated men: $40 \%$ of $25-64$ year-old women now have a tertiary degree on average across OECD countries, up from 30\% in 2008. In contrast, 34\% of 25-64 year-old men were tertiary educated in 2018, an increase of 7 percentage points since 2008. Women also outnumber men among new entrants at every level of tertiary education. On average across OECD countries, women make up 53\% of new entrants at short-cycle tertiary level, 54\% at bachelor's level, and 61\% at master's level (OECD, 2019 $\left.{ }_{[1]}\right)$.

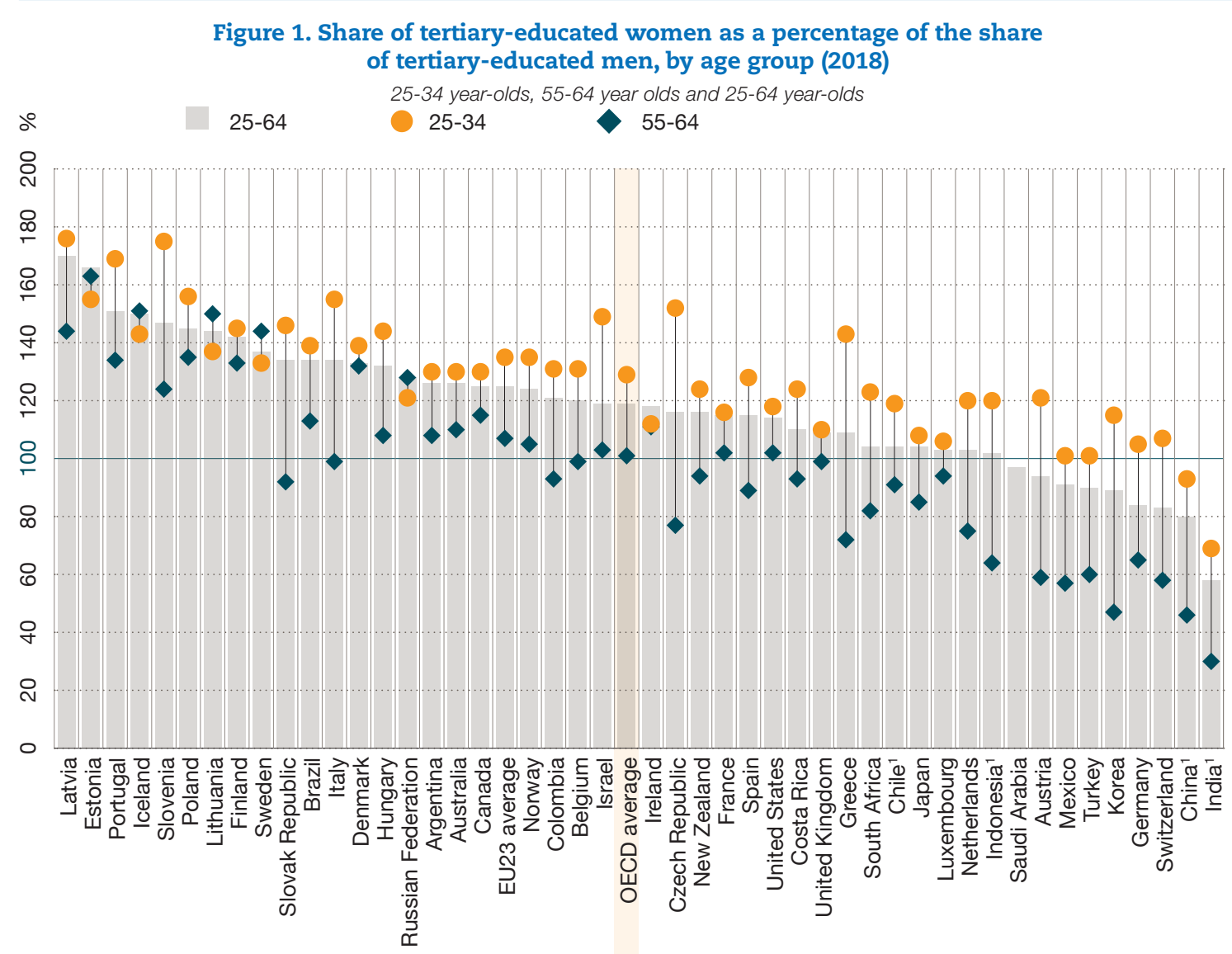

1. Year of reference differs from 2018. Refer to Education at a Glance 2019 for details.

Countries are ranked in descending order of the percentage point difference for 25-64 year-olds.

Source: OECD $\left(2019_{[1]}\right)$, Education at a Glance 2019: OECD Indicators, https://doi.org/10.1787/f8d7880d-en.

1 Values reported in equivalent US dollars (USD) have been converted using purchasing power parities (PPPS) for gross domestic product (GDP). 
Comparing the distribution of tertiary-educated men and women across generations can provide insights into the evolution of women's tertiary participation over time. On average across OECD countries, among 55-64 year-olds, the share of women with tertiary attainment is $4 \%$ higher than the share of men, but this rises to 32\% higher among 25-34 year-olds (Figure 1). In contrast, in Estonia, Iceland, Lithuania, the Russian Federation and Sweden, the gender gap in tertiary attainment is wider among older adults than younger ones.

The literature on women's participation in higher education highlights demographic, sociological, economic and educational factors as major reasons for this reversal of gender inequalities. The demographic factors, which correspond to women choosing to marry and have their first child later in life, as well as limiting their family size, enabled greater participation of women in higher education and a reduction in drop-out rates. Sociological factors combine various dimensions: women choosing to combine having a family with a professional life, the decline in discrimination against girls within families, gender-oriented parental models and girls' responses to gender stereotypes. The economic factors relate to both the higher return than before for women on studies in higher education and degrees, and the alternatives to higher education that have led to lower male participation. Finally, educational factors relate to the fact that in recent years girls have seen many improvements in their academic preparation compared with boys and have greater educational and professional expectations than their male peers (Vincent-Lancrin, 2008 ${ }_{[2]}$ ).

\section{...but gender gaps in subject choices persist and are often rooted much earlier in students' academic careers}

The positive trends in women's overall participation in higher education does not mean that the choice of field of studies remains free of gender bias. Fields of study are still highly influential on women's career choices and employment outcomes.

For example, women are far more likely than men to study subjects relating to education, and health and welfare. Men, for their part, are more likely to choose the broad fields of science, technology, engineering and mathematics (STEM), which are in great demand in the labour market in OECD countries. The focus on STEM education is particularly important, not as an end itself but because several components of STEM education encourage students to develop a critical thinking, identify connections between different disciplines and strengthen research competencies, among other skills. On average across OECD countries in 2017, women made up 20\% of new entrants to short-cycle tertiary programmes and $30 \%$ of new entrants to bachelor's programmes in STEM fields. In contrast, women made up $79 \%$ of new entrants to health and welfare short-cycle tertiary programmes, compared to $77 \%$ at bachelor's level and 64\% for master's long first degrees (OECD, 2019 ${ }_{[1]}$ ). There is greater gender equality among new entrants into master's long first degrees in both health and welfare and STEM fields.

Comparing the wider tertiary-educated population (25-64 year-olds) with current graduates highlights changes in fields of study over time for both men and women (Figure 2). On average across OECD countries, the most common fields of study for men are business, administration and law, and engineering, manufacturing and construction, while women are more likely to earn degrees in business administration and law, arts, humanities, social sciences, information and journalism. These patterns have not changed much across both population groups. However, there have been changes in the distribution across fields of study. While the total share of graduates in engineering, manufacturing and construction has decreased compared to the tertiary-educated adult population, this is mostly due to a lower participation of men. In contrast, engineering, manufacturing and construction appears to have become a slightly more attractive option for women: $7 \%$ of women tertiary graduates earned a degree in engineering, manufacturing and construction in 2017 compared to 6\% among tertiary-educated 2564 year-olds on average across OECD countries. Similarly, the arts, humanities, and social sciences are also losing attractiveness for men. The share of male tertiary graduates with a degree in these fields has dropped by about 5 percentage points on average compared to their share in the population, while the share of women graduating with a degree in these fields has remained stable across age groups. In contrast, more tertiary graduates are earning degrees in health and welfare: the share of men and women graduates from these fields is respectively 5 and 2 percentage points higher than their share among tertiary-educated adults on average across OECD countries. 
Figure 2. Distribution of male and female recent tertiary graduates by field of study, compared with fields of study of all tertiary-educated $25-64$ year-olds $(2017,2018)$

On average across OECD countries

Distribution of male recent graduates and tertiary-educated 25-64 year-olds

25-64 years-old adults (2018)

Graduates (2017)

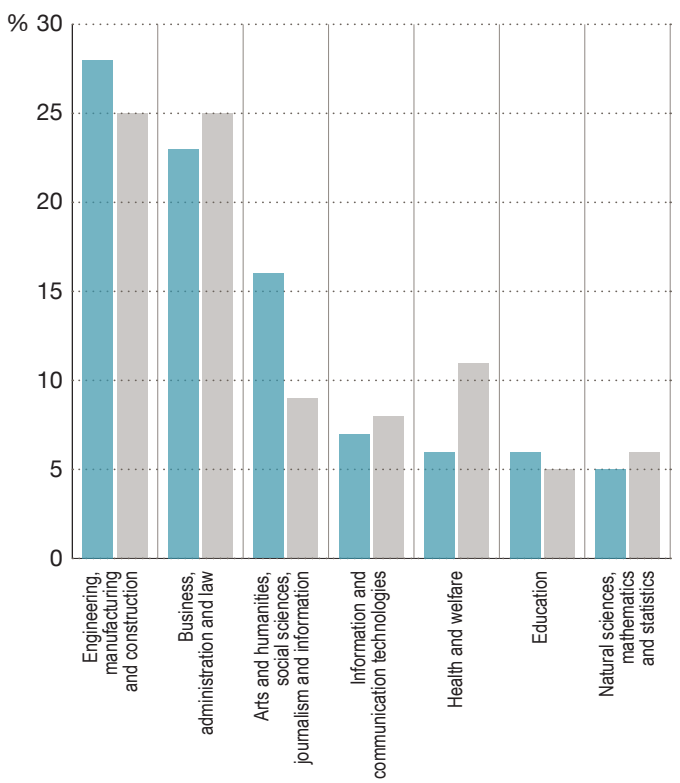

Distribution of female recent graduates and tertiary-educated 25-64 year-olds

25-64 years-old adults (2018) Graduates (2017)

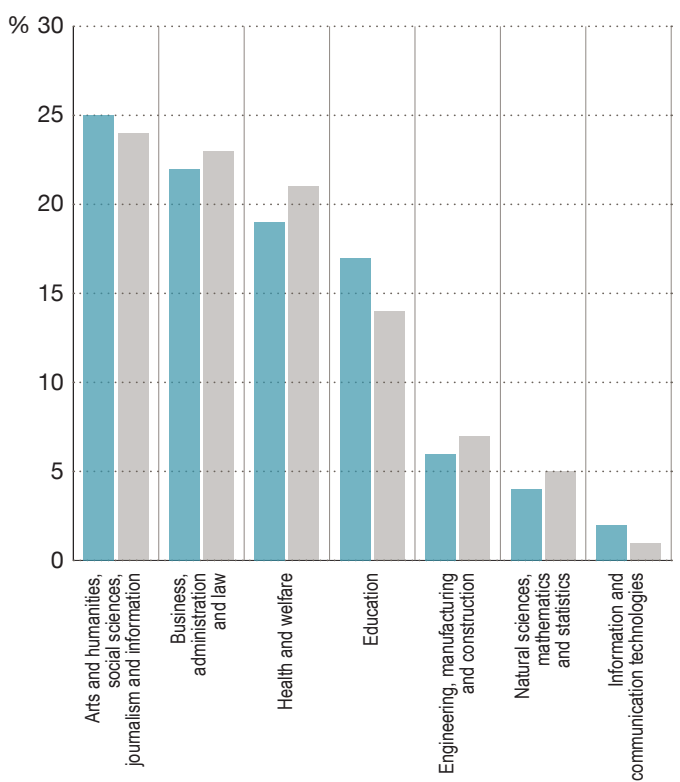

Fields are ranked in descending order of the distribution of all tertiary-educated 25-64 year-olds (2018).

Source: OECD (2019), Education at a Glance Database, https://stats. oecd.org/.

Gender differences in tertiary education choices are mirrored in the career expectations of 15-yearolds: on average across OECD countries, only 14\% of the girls who were top performers in science or mathematics reported that they expect to work in science or engineering, compared with $26 \%$ of topperforming boys. However, in Estonia, Finland, Poland and Slovenia, top-performing boys and girls were equally likely to report that they expect to work in those fields (OECD, 2019 ${ }_{[3]}$ ).

This difference is related neither to girls' level of academic performance nor their ambitions, but mainly to a lack of self-confidence. Girls are less likely than boys to believe in their own abilities, especially in mathematics, widening the gender gap in science-related careers. Some studies have highlighted the roles of stereotype threat and growth mindsets in women's low self-confidence when considering careers related to scientific subjects. Stereotype threat relates to the fact that women underperform in STEM academic tests when they have been exposed to negative stereotypes about their own achievements in science-related fields. On the other hand, a growth mindset - the belief that mathematics ability can be learned, instead of a trait inherited at birth and independent of efforts - can be a strength for those who hold it, but is relatively less common among women (Perez-Felkner, Nix and Thomas, 2017 ${ }_{[4]}$ ). The PISA survey also reveals some factors that influence girl's self-confidence in science: parents, peers and teacher's expectations of girl's abilities in science can be central to their success and reduces their anxiety whereas a lack of role models could stunt girl's confidence in their abilities (OECD, 2019 ${ }_{[3]}$ ).

\section{On average, with a degree in the same field of study, women's earnings in the workplace lag behind men's}

Despite higher educational attainment, women tend to earn less than their male counterparts, even for the same qualifications. The literature on the subject has suggested many fundamental reasons for women's slower earnings' progression in the workplace compared to men including differences in leadership style between men and women, the fact that women tend to be more modest and uncompetitive in the workplace, and women's greater reluctance to initiate negotiations about salaries (Heilman, 2012 $2_{[5]}$. 
Moreover, women start lower and progress more slowly in the workplace throughout their careers. Parenthood may lead to women working part time, which in turn temporarily reduces their opportunities for wage progression. Similarly, family policies such as parental leave, which are meant to support women combining parenthood and employment, actually undermine their ability to progress, whereas they have barely any effect on men's working patterns. This effect tends to be larger among highly educated women as their opportunity cost of part-time working is higher. However, a significant portion of the gender gap in wage progression remains unexplained and, on average, women face a wage gap of around $10 \%$ even before the arrival of their first child (Dias, Joyce and Parodi, $2018_{[6]}$ ).

The difference in earnings between men and women is widening. Given equivalent degrees, women's earnings are still below men's in any field of study and in all OECD and partner countries. Tertiaryeducated women working full time earn only $75 \%$ of the earnings of tertiary-educated men, on average across OECD countries (Figure 3). This gender pay gap exists for all fields of study but varies across them: it is smaller than the average for the fields of education and information and communication technologies (ICT) and larger for the field of business, administration and law.

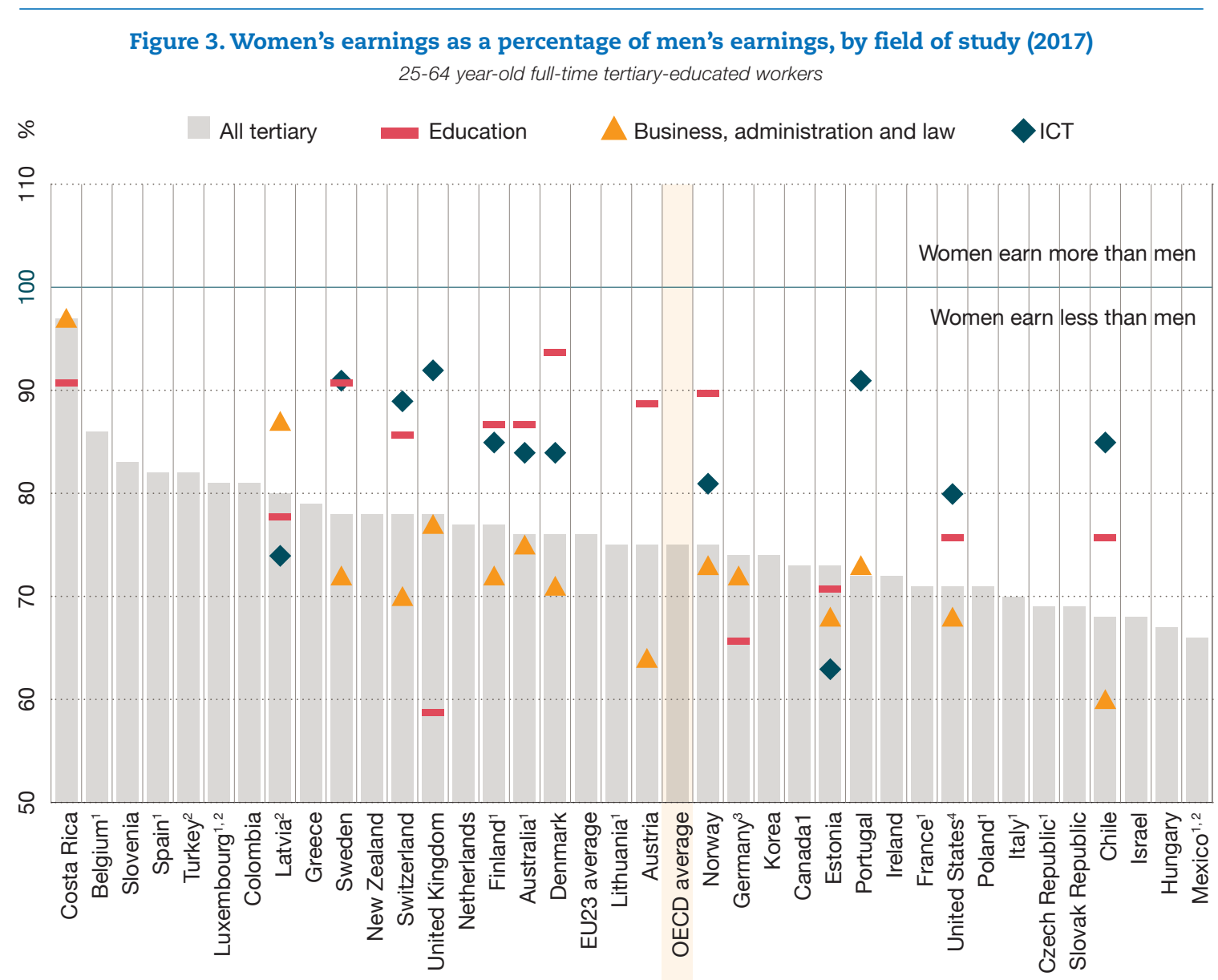

1. Year of reference differs from 2017. Refer to Education at a Glance 2019 for details 2. Earnings net of income tax.

3. Earnings by field refer to academic programmes only.

4. Earnings by field refer to the field of study at the bachelor's level.

Countries are ranked in descending order of women's earnings (all tertiary) as a percentage of men's earnings.

Source: OECD (2019[1]), Education at a Glance 2019: OECD Indicators, https://doi.org/10.1787/f8d7880d-en. 


\section{The bottom line}

Women's participation in higher education has overtaken men's. However, women have been historically under-represented in some fields and continue to be so: they predominate in education, and health and welfare as their main fields of study, while men predominate in science, technology, engineering and mathematics. Whatever field of study they choose, however, women's earnings still lag behind men's in all fields and in all OECD and partner countries.

\section{REFERENCES :}

[6] Dias, M., R. Joyce and F. Parodi (2018), "Wage progression and the gender wage gap: The causal impact of hours of work", IFS Briefing Note, No. BN223, Institute for Fiscal Studies, http://dx.doi.org/10.1920/BN.IFS.2018.BN0223.

[5] Heilman, M. (2012), "Gender stereotypes and workplace bias", Research in Organizational Behavior, Vol. 32, pp. 113-135, https://doi.org/10.1016/j.riob.2012.11.003.

[1] OECD (2019), Education at a Glance 2019: OECD Indicators, OECD Publishing, Paris, https://doi.org/10.1787/f8d7880d-en.

[3] OECD (2019), PISA 2018 Results (Volume II): Where All Students Can Succeed, OECD Publishing, Paris, https://doi.org/10.1787/b5fd1b8f-en.

[4] Perez-Felkner, L., S. Nix and K. Thomas (2017), "Gendered pathways: How mathematics ability beliefs shape secondary and postsecondary course and degree field choices", Frontiers in Psychology, http://dx.doi.org/10.3389/fpsyg.2017.00386.

[2] Vincent-Lancrin, S. (2008), "The Reversal of gender inequalities in higher education: An ongoing trend", in Higher Education to 2030, Volume 1, Demography, OECD Publishing, Paris, https://doi.org/10.1787/9789264040663-11-en.

VISIT

www.oecd.org/education/education-at-a-glance-19991487.htm

Education Indicators in Focus (previous issues)

PISA in Focus

Teaching in Focus

How does earnings advantage from tertiary education vary by field of study?

Photo credit: @ Christopher Futcher / iStock; @ Marc Romanelli / Gettyimages; @ michaeljung / Shutterstock; @ Pressmaster / Shutterstock This work is published under the responsibility of the Secretary-General of the OECD. The opinions expressed and arguments employed herein do not necessarily reflect the official views of OECD member countries.

This document, as well as any data and any map included herein, are without prejudice to the status of or sovereignty over any territory, to the delimitation of international frontiers and boundaries and to the name of any territory, city or area.

The statistical data for Israel are supplied by and are under the responsibility of the relevant Israeli authorities. The use of such data by the OECD is without prejudice to the status of the Golan Heights, East Jerusalem and Israeli settlements in the West Bank under the terms of international law. 